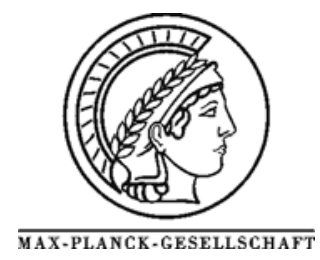

\title{
On the CO-oxidation over oxygenated Ruthenium
}

\author{
D. Rosenthal*, F. Girgsdies, O. Timpe, R. Blume, G. Weinberg, D. Teschner, R. Schlögl
}

Department of Inorganic Chemistry, Fritz-Haber-Institute of the MPG, Faradayweg 4-6, 14195 Berlin, Germany

\section{Dedicated to Prof. Dr. Klaus Christmann on the occasion of his $65^{\text {th }}$ birthday}

*Corresponding author: e-mail dirkrose@fhi-berlin.mpg.de, phone +49 308413 4523, fax +493084134401

Received: 15 September 2008, accepted 10 October 2008; Published Online: 29 Jan 2009

\begin{abstract}
The oxidation of carbon monoxide over polycrystalline ruthenium dioxide $\left(\mathrm{RuO}_{2}\right)$ powder was studied in a packed-bed reactor and by bulk and surface analytical methods. Activity data were correlated with bulk phases in an in-situ X-ray diffraction (XRD) setup at atmospheric pressure. Ruthenium dioxide was pre-calcined in pure oxygen at $1073 \mathrm{~K}$. At this stage $\mathrm{RuO}_{2}$ is completely inactive in the oxidation of $\mathrm{CO}$. After a long induction period in the feed at $503 \mathrm{~K} \mathrm{RuO}_{2}$ becomes active with $100 \%$ conversion, while in-situ $\mathrm{XRD}$ reveals no changes in the $\mathrm{RuO}_{2}$ diffraction pattern. At this stage selective roughening of apical $\mathrm{RuO}_{2}$ facets was observed by scanning electron microscopy (SEM). Seldom also single lateral facets are roughened. EDX indicated higher oxygen content in the following order: flat lateral facets $>$ rough lateral facets $>$ rough apical facets. Further, experiments in the packed bed reactor indicated oscillations in the $\mathrm{CO}_{2}$ formation rate. At even higher temperatures in reducing feed $(533-543 \mathrm{~K})$ the sample reduces to ruthenium metal according to XRD. The reduced particles exhibiting lower ignition temperature are very rough with cracks and deep star-shaped holes. An Arrhenius plot of the $\mathrm{CO}_{2}$ formation rate below the ignition temperature reveals the reduced samples to be significantly more active based on mass unit and shows lower apparent activation energy than the activated oxidized sample. Micro-spot X-ray photoelectron spectroscopy (XPS) and XPS microscopy experiments were carried out on a Ru(0001) single crystal exposed to oxygen at different temperature. Although low energy electron diffraction (LEED) images show a strong $1 \mathrm{x} 1$ pattern, the XPS data indicated a wide lateral inhomogeneity with different degree of oxygen dissolved in the subsurface layers. All these and the literature data are discussed in the context of different active states and transport issues, and the metastable nature of a phase mixture under conditions of high catalytic activity.
\end{abstract}

Keywords: Ruthenium; CO-oxidation; in-situ XRD; oscillation

\section{Introduction}

$\mathrm{CO}$ oxidation over transition metals is a widely investigated reaction due to its apparent simplicity. The pioneering works of Gerhard Ertl and co-workers on the oscillatory behavior of this reaction over platinum surfaces, however, demonstrated a higher degree of complexity [1]. In comparison to other platinum metals, the situation seems to be even more complex for ruthenium, as it shows the lowest activity under UHV conditions [2] while being a very potent catalyst at high pressures [3]. There is consensus in the literature that the activity strongly depends on the partial pressures of $\mathrm{CO}$ and $\mathrm{O}_{2}$. Yet, the nature of the active state in the ruthenium/oxygen system is still heavily de- bated [4-6]. Three main models are under consideration in the literature:

1. In an early paper of Peden and Goodman [3], the $\mathrm{Ru}(0001)-(1 \mathrm{x} 1)$ oxygen terminated surface, with $1 \mathrm{ML}$ of oxygen, was found to be very active, comparable to supported Ru-catalysts.

2. Later, Over et al. [7] proposed that weakly bonded oxygen on coordinatively unsaturated sites (cus-O) of the $\mathrm{RuO}_{2}(110)$ surfaces are the active species. Whereas these aforementioned studies dealt with ruthenium single crystals, in more recent work on polycrystalline ruthenium dioxide [8] the authors proposed a core-shell model consisting of an about $1 \mathrm{~nm}$ thick $\mathrm{RuO}_{2}$ layer covering a metallic core as the most active 
state of $\mathrm{RuO}_{2}$ in the $\mathrm{CO}$ oxidation. Again, the cus-oxygen was suggested as the active species, thus the authors concluded that the "pressure gap" was bridged $[9,10]$. The observed deactivation behavior, especially under net-oxidizing conditions, was attributed to the formation of the completely inactive $\mathrm{RuO}_{2}(100)-\mathrm{c}(2 \times 2)$ surface $[10,11]$.

3. The third model was introduced by Böttcher et al.[2,12], indicating that subsurface oxygen dissolved in ruthenium [2] as well as a surface oxide [13], i.e. oxygen after completion of the $\mathrm{Ru}(0001)-(1 \mathrm{x} 1)$ O-phase but before the growth of $\mathrm{RuO}_{2}$ was responsible for the high activity without the formation of $\mathrm{RuO}_{2}$ being necessary. This so-called transient surface oxide (TSO) was at first described as O-Ru-O trilayer in a density functional theory study by Reuter et al. [14].

Since the three models encompass the whole range from metallic $\mathrm{Ru}$ (covered with one monolayer oxygen) to fully oxidized $\mathrm{RuO}_{2}$ and all phases are potentially interconvertible under reaction conditions, in-situ analytical methods should be very potent tools to investigate this reaction. Up to now, only three papers report on in-situ studies of the catalyst structure for the $\mathrm{CO}$ oxidation on ruthenium. While one dealt with in-situ XRD on $\mathrm{Ru}_{\mathrm{x}} \mathrm{O}_{\mathrm{y}^{-}}$ like nanoparticles [15], another probed only the wellordered part of the $\mathrm{Ru}(0001)$ surface during oxidation in oxygen or $\mathrm{CO}$ and $\mathrm{O}_{2}$ reaction atmosphere by in-situ Surface XRD [16], in the last the surface state of $\mathrm{Ru}(0001)$ was investigated during $\mathrm{CO}$ oxidation with in-situ X-ray photoelectron spectroscopy (XPS) [17]. In the work presented here, we used polycrystalline $\mathrm{RuO}_{2}$ powder as natural link between single crystals in UHV studies and supported nanoparticles in catalysis. Since the chemical potential of the reaction feed affects the stoichiometry of the catalyst we combined catalytic tests with in-situ XRD to probe the bulk state of the catalyst under reaction conditions. Supplemented by XPS microscopy and SEM we will address the following questions:

1. What is the bulk state of the catalyst during reaction conditions?

2. Is there necessarily only one type of active state of ruthenium (i.e. one of the previously proposed three models) for the whole parameter space of the reaction?

\section{Experimental}

Catalytic experiments were carried out in a quartz tube reactor with an inner diameter of $7.5 \mathrm{~mm} .30 \mathrm{mg}$ of commercial $\mathrm{RuO}_{2}$ powder (Johnson Matthey) was ground in a mortar with $50 \mathrm{mg}$ hexagonal $\mathrm{BN}$ and subsequently mixed with $100 \mathrm{mg} \mathrm{SiC}$. The catalyst bed was fixed by quartz wool. Gases with purity $>99.999 \%$ for $\mathrm{He}$ and $\mathrm{O}_{2}$ and $>99.997 \%$ for CO were supplied by mass flow controllers (Bronkhorst). CO oxidation was carried out under net reducing $\left(\mathrm{CO} / \mathrm{O}_{2}: 3.1 / 1 ; 3.8 \mathrm{Nml} / \mathrm{min} \mathrm{O}_{2}\right)$, oxidizing
$\left(\mathrm{CO} / \mathrm{O}_{2}: 1 / 1.8 ; \quad 9.8 \mathrm{Nml} / \mathrm{min} \quad \mathrm{O}_{2}\right)$ and stoichiometric $\left(\mathrm{CO} / \mathrm{O}_{2}: 2 / 1,4.9 \mathrm{Nml} / \mathrm{min} \mathrm{O}_{2}\right)$ feed conditions. The total flow rate was always set to $100 \mathrm{Nml} / \mathrm{min}$ by adding $\mathrm{He}$ to the mixture. The temperature was measured by two thermocouples at different positions: the one used for temperature control was placed outside the quartz tube next to the catalyst bed, while the second one was placed in the gas stream against the catalyst bed, thus measuring the temperature of the gas feed before entering the catalyst bed. The reaction was monitored using a quadrupole mass spectrometer (Pfeiffer/Balzers, Prisma QMS 200) attached with a capillary to the gas outlet. Blind experiments were carried out with a mixture of $60 \mathrm{mg} \mathrm{BN}$ and $120 \mathrm{mg} \mathrm{SiC}$. No significant $\mathrm{CO}_{2}$ formation was observed. Conversion calculations of $\mathrm{CO}$ and $\mathrm{O}_{2}$ based on the (normalized) MS signals and were calculated as follows (only given for $\mathrm{CO}$ ):

conversion of $C O=\frac{M S_{C O}^{\text {in }}-M S_{C O}^{\text {out }}}{M S_{C O}^{\text {in }}} \times 100$

where $M S_{C O}^{\text {in }}$ and $M S_{C O}^{\text {out }}$ are the inlet and outlet MS signals, respectively. The yield of $\mathrm{CO}_{2}$ was calculated by the conversion of $\mathrm{CO}$ and $\mathrm{O}_{2}$. The commercial $\mathrm{RuO}_{2}$ powder exhibits a BET surface area of $1 \mathrm{~m}^{2} / \mathrm{g}$. XRD shows small amounts of metallic ruthenium in addition to the $\mathrm{RuO}_{2}$ phase. SEM reveals small particles in the range of several tens of nm diameter as well as large particles up to several $\mu \mathrm{m}$. EDX verified the XRD result showing some aggregates of particles with an overall stoichiometry of RuO. In a series of experiments, it turned out that calcination in pure oxygen at temperatures well above $1000 \mathrm{~K}$ was necessary to obtain pure $\mathrm{RuO}_{2}$ (according to XRD and EDX) from the as-purchased material. Consequently, the $\mathrm{RuO}_{2}$ powder mixture (with $\mathrm{BN}$ and $\mathrm{SiC}$ ) was calcined at $1073 \mathrm{~K}$ in $30 \mathrm{Nml} / \mathrm{min}$ pure oxygen for one hour prior to reaction.

\subsection{In situ X-ray diffraction}

The in situ XRD data were collected on a STOE Theta/theta X-ray diffractometer ( $\mathrm{CuK} \alpha$ radiation, secondary graphite monochromator, scintillation counter) equipped with an Anton Paar XRK 900 in-situ reactor chamber. A simplified sketch of the in situ reactor chamber with marked gas flow is shown in fig. 1. The walls of the reactor (and hence the entrance and outlet points of the gases through the walls) were kept at $298 \mathrm{~K}$ by a cooling water thermostat. In order to obtain a plain, smooth sample surface at the correct height for the diffraction experiment, the amount of sample had to be chosen to fill the volume of the sample holder. The resulting catalyst bed was $14 \mathrm{~mm}$ in diameter with a height of less than $1 \mathrm{~mm}$, corresponding to 110-130 mg sample. The commercial $\mathrm{RuO}_{2}$ powder (Acros organics) was calcined $\left(1073 \mathrm{~K}, 5\right.$ hours, $30 \mathrm{Nml} / \mathrm{min} \mathrm{O}_{2}$ ) and mixed with boron nitride in a weight ratio of 3:5. Blind experiments were carried out with pure BN. No significant 
$\mathrm{CO}_{2}$ formation was observed. The temperature was measured by two type $\mathrm{K}$ thermocouples. While the first one (TC1) was in close contact to the catalyst bed, the second thermocouple (TC2) was situated near the entrance of the gases. The temperature reading of the second thermocouple was generally below the temperature of the catalyst bed due to the cooling effect of the incoming gases. Temperatures up to $600^{\circ} \mathrm{C}$ could be easily reached under the used flow conditions. The reaction gas feed was mixed by means of mass flow controllers (Bronkhorst), using helium as inert balance gas at a total flow rate of $100 \mathrm{Nml} / \mathrm{min}$. The effluent product gas composition and thermocouple readouts were monitored with a Pfeiffer OmniStar quadrupole mass spectrometer. The reactor was assumed as a packed bed flow-type and hence the calculation of the conversion of $\mathrm{CO}$ and $\mathrm{O}_{2}$ and the yield of $\mathrm{CO}_{2}$ were calculated as in the case for the quartz tube reactor.

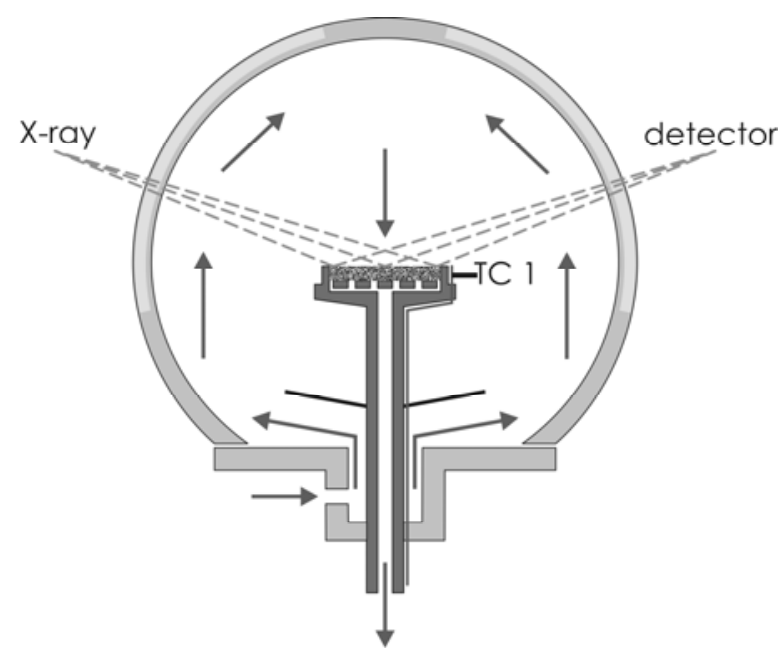

Fig. 1: Simplified sketch of the in-situ reactor chamber with indication of gas flow (arrows), thermocouple close to the catalyst (TC1) and X-ray beam path. The heater coils, two concentric heat shields, the second thermocouple and two more gas entry points are omitted for clarity.

\subsection{X-ray photoelectron spectroscopy (XPS) and XPS microscopy}

XPS microscopy experiments were carried out with a scanning photoemission microscope (SPEM) operating at the ESCA microscopy beamline at Elettra. The SPEM uses a zone plate as photon focusing optic and a hemispherical electron energy analyzer with a 48 channel detector [18]. It can be operated in imaging as well as in microspot XPS mode. Whereas in the latter spectra are recorded in a chosen area of the sample, in the former mode electrons of a given energy window emitted from the sample are collected by stepwise scanning of the surface. Thus, the resulting images of the surface reflect lateral variations in concentration and chemical state of a chosen element.

The measurements were performed with photon energies of $450 \mathrm{eV}$, an energy resolution of $0.18 \mathrm{eV}$ and a lateral resolution of $150 \mathrm{~nm}$. This results in an effective escape depth for $\mathrm{Ru} 3 \mathrm{~d}$ photoelectrons in our grazing geometry as estimated to be $\sim 3.8 \AA$ [19]. Hence, the useful information depth is limited exclusively to the two topmost layers with an average information volume in the order of $1000 \mathrm{~nm}^{3}$.

The $\mathrm{Ru} 3 \mathrm{~d}_{5 / 2}$ spectra were fitted by using asymmetric Doniach-Sunjic functions convoluted with Gaussian profiles, following the strategy described in [20]. The accuracy of the peak positions for the different fits is better than $0.05 \mathrm{eV}$. In the deconvolution procedure for the disordered phases with ill-defined multiple coordination, broadening of the fit components was allowed.

A clean, well-ordered $\mathrm{Ru}(0001)$ surface was obtained by cycles of $\mathrm{Ar}^{+}$sputtering and subsequent annealing in $\mathrm{O}_{2}$ ambient, as described in [21]. The oxidation was carried out in a high-pressure chamber connected to the microscope UHV chamber. The sample temperature was controlled with a type $\mathrm{K}$ thermocouple spot welded to the backside of the sample.

\subsection{Scanning electron microscopy (SEM)}

The SEM experiments were conducted in the secondary electron mode with a Hitachi S-4800 (FEG) instrument equipped with an EDAX Genesis4000 system for energy dispersive X-ray (EDX) analysis. Low acceleration voltages of $2 \mathrm{kV}$ were used for the micrographs in order to enhance the surface sensitivity. EDX spectra were obtained by using an accelerating voltage of $5 \mathrm{kV}$. After cooling down in the reaction atmosphere the samples were directly transferred (exposed to air) from the reactor to the SEM without further treatment.

\section{Results}

\subsection{Catalytic experiments}

In order to elucidate the activity of the initial fully oxidized ruthenium dioxide sample, it was exposed to various reactant stoichiometries. The conversion of the respective minority reactant of all experiments is depicted in Figure 2. The order of experiments was as follows: 1. oxidizing feed; 2 . reducing feed and 3. stoichiometric feed. Please note that the $2^{\text {nd }}$ and $3^{\text {rd }}$ experiments were carried out using the sample of the $1^{\text {st }}$ run, that is, not with fresh material.

1. In the first experiment, the catalyst bed temperature was ramped $(5 \mathrm{~K} / \mathrm{min})$ to $476 \mathrm{~K}$ in a stoichiometric feed. After reaching the target temperature, the sample still did not show any catalytic activity. Subsequently, the feed was switched to net-oxidizing conditions $\left(\mathrm{CO}: \mathrm{O}_{2} \approx 1: 2\right.$, $9.8 \mathrm{Nml} / \mathrm{min} \mathrm{O}_{2}$ ). The temperature was then increased in steps of $1 \mathrm{~K}$ every $25 \mathrm{~min}$ up to $503 \mathrm{~K}$. After establishing the net-oxidizing feed, the reaction shows a long induction period with slowly increasing activity, until ignition occurs 
after a period of more than $250 \mathrm{~min}$. The conversion of CO is shown in figure 2 . The observed activity exhibits a complex oscillation pattern, which seems to result from convolution of two processes with different time constants. A detailed picture is shown in figure 3. The low frequency oscillation (with a period in the range between 50 and 100 min) involves steep changes between low and high activity (ignition/extinction). In the low activity regime, the activity increases slowly but with increasing speed, similar to the initial activation behavior. The high activity regime shows high frequency oscillations on the few minutes timescale, with spikes of lower activity of continuously increasing amplitude until extinction occurs. The quantity of the converted $\mathrm{CO}$ molecules during one high frequency oscillation is in the range of one $\mathrm{CO}$ molecule per $\mathrm{RuO}_{2}$ surface unit cell considering the surface area being $1 \mathrm{~m}^{2} / \mathrm{g}$ as for the original commercial $\mathrm{RuO}_{2}$. Due to the high exothermicity of the $\mathrm{CO}$ oxidation the high activity range is accompanied by strong heat production in the catalyst bed leading to a reduction of the heating power and thus a decrease of the temperature in the inlet feed. After more than 10 hours on stream the reaction was interrupted at the state of high activity by cooling down to room temperature.

In order to elucidate the activity of the initial fully oxidized ruthenium dioxide sample, it was exposed to various reactant stoichiometries. The conversion of the respective minority reactant of all experiments is depicted in Figure 2. The order of experiments was as follows: 1. oxidizing feed; 2 . reducing feed and 3. stoichiometric feed. Please note that the $2^{\text {nd }}$ and $3^{\text {rd }}$ experiments were carried out using the sample of the $1^{\text {st }}$ run, that is, not with fresh material.

1. In the first experiment, the catalyst bed temperature was ramped $(5 \mathrm{~K} / \mathrm{min})$ to $476 \mathrm{~K}$ in a stoichiometric feed. After reaching the target temperature, the sample still did not show any catalytic activity. Subsequently, the feed was switched to net-oxidizing conditions $\left(\mathrm{CO}: \mathrm{O}_{2} \approx 1: 2\right.$, $9.8 \mathrm{Nml} / \mathrm{min} \mathrm{O}_{2}$ ). The temperature was then increased in steps of $1 \mathrm{~K}$ every $25 \mathrm{~min}$ up to $503 \mathrm{~K}$. After establishing the net-oxidizing feed, the reaction shows a long induction period with slowly increasing activity, until ignition occurs after a period of more than $250 \mathrm{~min}$. The conversion of CO is shown in figure 2 . The observed activity exhibits a complex oscillation pattern, which seems to result from convolution of two processes with different time constants. A detailed picture is shown in figure 3. The low frequency oscillation (with a period in the range between 50 and 100 min) involves steep changes between low and high activity (ignition/extinction). In the low activity regime, the activity increases slowly but with increasing speed, similar to the initial activation behavior. The high activity regime shows high frequency oscillations on the few minutes timescale, with spikes of lower activity of continuously increasing amplitude until extinction occurs. The quantity of the converted $\mathrm{CO}$ molecules during one high frequency oscillation is in the range of one $\mathrm{CO}$ molecule per $\mathrm{RuO}_{2}$ surface unit cell considering the surface area being $1 \mathrm{~m}^{2} / \mathrm{g}$ as for the original commercial $\mathrm{RuO}_{2}$. Due to the high exothermicity of the $\mathrm{CO}$ oxidation the high activity range is accompanied by strong heat production in the catalyst bed leading to a reduction of the heating power and thus a decrease of the temperature in the inlet feed. After more than 10 hours on stream the reaction was interrupted at the state of high activity by cooling down to room temperature.

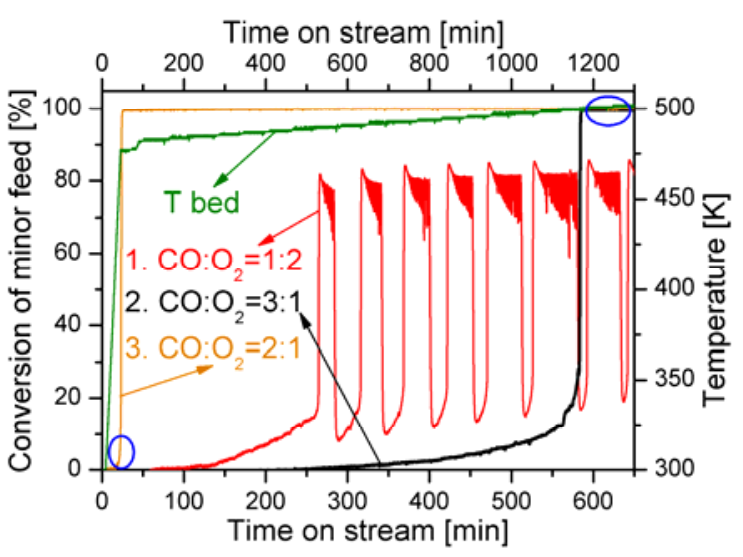

Fig. 2: (Color online) Comparison of three consecutive experiments with varying feed composition. After calcination, the first experiment used oxidizing feed $\left(\mathrm{CO}: \mathrm{O}_{2} \approx 1: 2\right.$, lower time scale), followed by a second run in reducing feed $\left(\mathrm{CO}: \mathrm{O}_{2} \approx 3: 1\right.$, upper time scale) and a third one in stoichiometric feed $\left(\mathrm{CO}: \mathrm{O}_{2} \approx 2: 1\right.$, upper time scale). Conversions are given for the respective minority compound, all feeds are $100 \mathrm{Nml} / \mathrm{min}$ total flow. The circles mark experiments where the active bulk phase is likely metallic (actY/Ru, see the part in-situ XRD and catalytic tests), for the activation under net-oxidizing conditions see the end of the part "In-situ XRD and catalytic tests".

2. The second experiment was conducted in direct continuation of the first one, i.e. without additional oxidizing pretreatment of the catalyst. The reaction temperature was ramped to $478 \mathrm{~K}$ in a stoichiometric gas feed, which was subsequently switched to net-reducing $\left(\mathrm{CO}: \mathrm{O}_{2} \approx 3: 1\right.$, $3.8 \mathrm{Nml} / \mathrm{min} \mathrm{O}_{2}$ ) conditions. Similar to the first run, the temperature was further increased stepwise $(1 \mathrm{~K}$ every 60 minutes) and finally held at $503 \mathrm{~K}$. Under reducing conditions, complete oxygen conversion is reached only after a very long induction period with slowly increasing conversion which finally leads to ignition at $496 \mathrm{~K}$ after $1170 \mathrm{~min}$ time on stream. As a response of the temperature control at the catalyst bed, the ignition caused the feed temperature (not shown) to be lowered by $20 \mathrm{~K}$ with respect to the bed temperature. It is interesting to note that during ignition the steady state $\mathrm{CO}_{2}$ intensity is reached only after an overshoot (Fig. 4). This overshoot is mirror-inverted by the CO MS signal but not by the oxygen signal. Since the gas phase is completely depleted of oxygen, the overshoot must have its origin in consuming oxygen stored in the sample. The additional $\mathrm{CO}$ consumption during the overshoot was calculated to be $260 \mu \mathrm{mol}$. Assuming that the necessary oxy- 
gen stems from the bulk of the ruthenium oxide, this amount would correspond to a reduction in overall stoichiometry from $\mathrm{RuO}_{\mathrm{x}}(\mathrm{x} \leq 2)$ to approximately $\mathrm{RuO}_{\mathrm{x}-1}(30 \mathrm{mg}$ $=226 \mu \mathrm{mol} \mathrm{RuO}_{2}$ ). After this reduction step the bulk state of the catalyst is very likely metallic and assigned later to actY/Ru (see part in-situ XRD and catalytic tests).

3. After cooling to room temperature, a third experiment was performed with stoichiometric feed $\left(\mathrm{CO}: \mathrm{O}_{2} \approx\right.$ $2: 1,4.9 \mathrm{Nml} / \mathrm{min} \mathrm{O}_{2}$ ) using the same temperature program as in the second run.. This experiment shows ignition directly during ramping to $478 \mathrm{~K}$ again accompanied by the decrease of the inlet feed temperature. An Arrhenius plot of the low conversion regime before ignition yields an apparent activation energy of $82 \mathrm{~kJ} / \mathrm{mol}$. No extinction of the activity is observed here, neither in the second experiment.

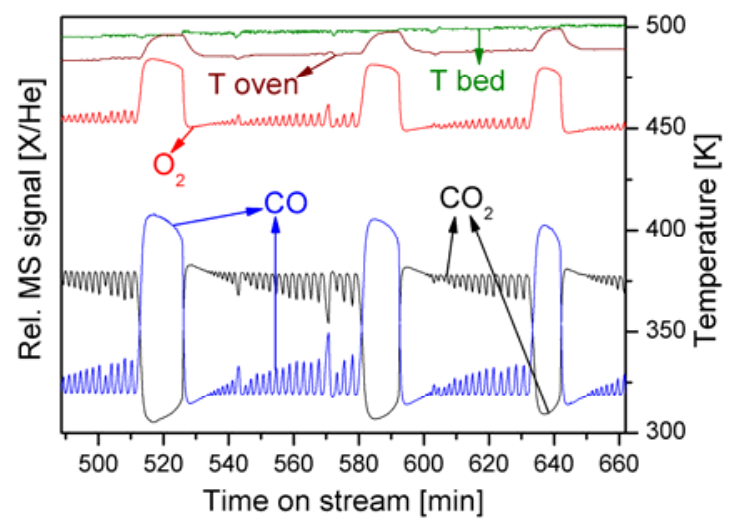

Fig. 3: (Color online) Oscillations in the MS signals (normalized to Helium) for $\mathrm{CO}(\mathrm{m} / \mathrm{e} \mathrm{28}), \mathrm{CO}_{2}(\mathrm{~m} / \mathrm{e} \mathrm{44})$ and $\mathrm{O}_{2}(\mathrm{~m} / \mathrm{e} 32)$, the temperatures of the catalyst bed (green) and the feed gas in front of the catalyst bed (brown). The feed was stoichiometric during ramping to $476 \mathrm{~K}$ and afterwards oxidizing $\left(\mathrm{CO}: \mathrm{O}_{2} \approx 1: 2,9.8 \mathrm{Nml} / \mathrm{min}\right.$ $\mathrm{O}_{2}$, total flow $100 \mathrm{Nml}$ ).

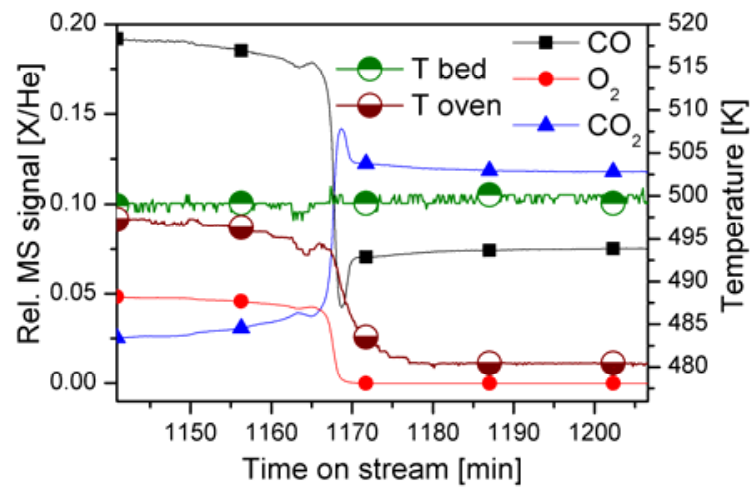

Fig. 4: (Color online) Detail of the ignition in the second run (reducing conditions), shown in fig. 2. The $\mathrm{CO}_{2}$ signal exhibits a clear overshoot, accompanied by a corresponding dip in the CO signal. In contrast, the oxygen signal shows a simple step profile without such dip.

\subsection{In-situ XRD and catalytic tests}

The observed oscillations under net-oxidizing conditions in the previous part could be due to switching in the bulk state of the catalyst. Therefore in situ XRD measurements were undertaken to follow the bulk state of the $\mathrm{Ru}$ catalyst during reaction conditions accompanied by monitoring the gas stream in the outlet. The first striking result is that (in contrast to the as-received $\mathrm{RuO}_{2}$ powder) the calcined, stoichiometric $\mathrm{RuO}_{2}$ is found to be completely inactive at $503 \mathrm{~K}$ over a period of at least three hours, no matter whether stoichiometric $\left(\mathrm{CO}: \mathrm{O}_{2} 10: 5\right)$, reducing $\left(\mathrm{CO}: \mathrm{O}_{2}\right.$ 12:3) or oxidizing $\left(\mathrm{CO}: \mathrm{O}_{2} \quad 5: 10\right)$ feeds were used (x:y means $\mathrm{x} \mathrm{Nml} / \mathrm{min} \mathrm{CO}, \mathrm{y} \mathrm{Nml} / \mathrm{min} \mathrm{O}_{2}$, balance He, $100 \mathrm{Nml} / \mathrm{min}$ total). Apart from temperature related shifts in the diffraction peaks (especially the 002 reflexion of $\mathrm{BN}$ ), no changes were detected in the XRD patterns. Thus, we tried to activate the calcined $\mathrm{RuO}_{2}$ in a strongly reducing feed $\left(\mathrm{CO}: \mathrm{O}_{2}\right.$ 14:1, fig. 5). After heating at $10 \mathrm{~K} / \mathrm{min}$ and four hours hold at $503 \mathrm{~K}$, the $\mathrm{CO}_{2}$ signal slowly starts to increase, giving rise to a sigmoid activation curve with the inflection point around 9 hours and still increasing conversion after 15 hours. Using stoichiometric $\left(\mathrm{CO}: \mathrm{O}_{2}\right.$ 10:5) feed instead, the activation starts later and the inflection point occurs after approximately 13 hours. In both cases, no changes in the XRD pattern are observed, i.e. the $\mathrm{RuO}_{2}$ bulk stays, within the detection limits of XRD, unaffected during the change from an inactive to an active state. In the following, we will refer to this active $\mathrm{RuO}_{2}$ state as "actX/RuO ${ }_{2}$ " (an active surface modification $\mathrm{X}$ on bulk $\mathrm{RuO}_{2}$ ). In a further experiment, the reaction atmosphere was changed directly after reaching the actX/RuO $\mathrm{R}_{2}$ state with the strongly reducing $\left(\mathrm{CO}: \mathrm{O}_{2} 14: 1\right)$ feed at $503 \mathrm{~K}$ to stoichiometric $\left(\mathrm{CO}: \mathrm{O}_{2}\right.$ 10:5) feed conditions. This leads to a fast (within $15 \mathrm{~min}$ ), almost complete reduction of the sample to Ru metal in XRD (some residual intensity of the $\mathrm{RuO}_{2} 110$ peak can still be seen) and a conversion of $100 \%$. At the first glance, it seems surprising that a decrease in the $\mathrm{CO}$ to $\mathrm{O}_{2}$ ratio results in bulk reduction. However, we have to consider that this feed-switching may lead to local overheating of the sample due to a sudden increase in the exothermic reaction rate. Such a local temperature increase, which is not reflected in the temperature reading of the controlling TC1 thermocouple, is indeed evidenced by a sudden shift seen in the $\mathrm{BN} 002$ reflection. In order to gain more insight into the reduction behaviour of the sample, we conducted an experiment where the active $\mathrm{RuO}_{2}$ $\left(\mathrm{actX} / \mathrm{RuO}_{2}\right)$ was heated in the strongly reducing $\left(\mathrm{CO}: \mathrm{O}_{2}\right.$ 14:1) feed to higher temperatures. The temperature was first raised from ambient to $473 \mathrm{~K}$ at $20 \mathrm{~K} / \mathrm{min}$, then diffraction patterns were taken every $10 \mathrm{~K}$ ( $85 \mathrm{~min}$ holds) up to $573 \mathrm{~K}$. The diffraction patterns show that the reduction to $\mathrm{Ru}$ metal starts at $533 \mathrm{~K}$ and is completed during the XRD scan at $543 \mathrm{~K}$. This second active state of the Ru catalyst we will refer to in the following as "actY/Ru" (since the active surface modification on bulk Ru metal is not necessarily the same as $\mathrm{X}$ we call it $\mathrm{Y})$. Representative $\mathrm{XRD}$ patterns of the actX/RuO 2 and actY/Ru samples are 
depicted in figure 6. Analysis of the diffraction peak width yields LVol-IB values (integral breadth based volume weighted column length, a measure for crystallite size [22]) of ca. $160 \mathrm{~nm}$ for $\mathrm{RuO}_{2}$ in actX/RuO and only $8 \mathrm{~nm}$ for $\mathrm{Ru}$ metal in actY/Ru.

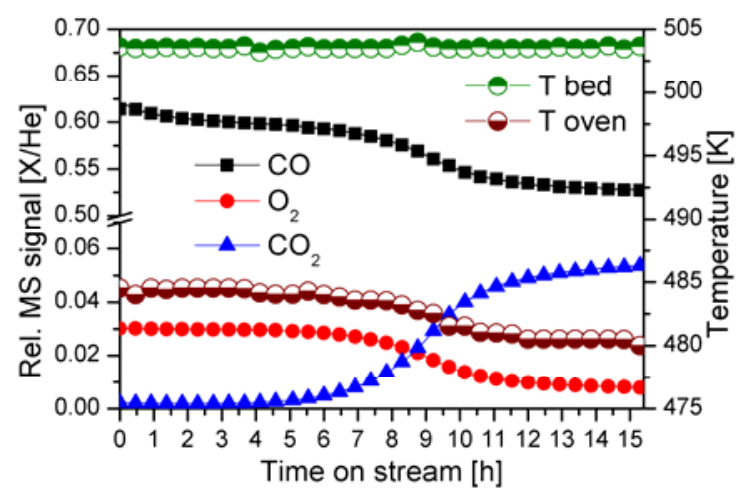

Fig. 5: (Color online) Activation of $\mathrm{RuO}_{2}$ to $\operatorname{actX} / \mathrm{RuO}_{2}$ in $\left(\mathrm{CO}: \mathrm{O}_{2}\right.$ $14: 1$ ) feed at $503 \mathrm{~K}$.

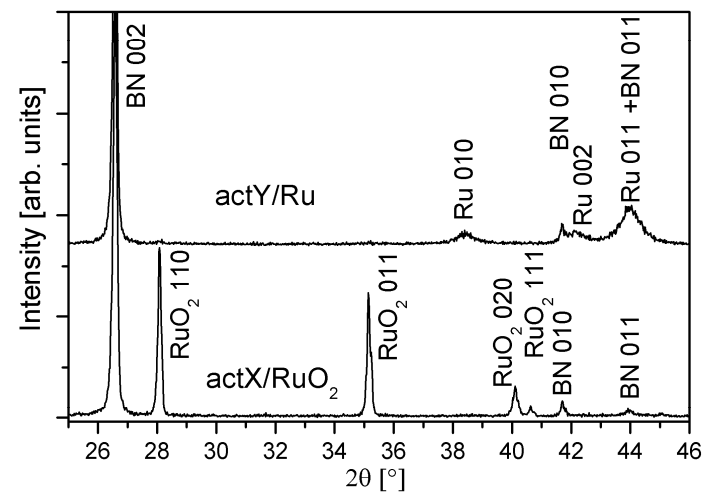

Fig. 6: Representative XRD patterns of the $\operatorname{act} \mathrm{X} / \mathrm{RuO}_{2}$ and actY/Ru states

In order to check how far the bulk is equilibrated with the gas phase under reaction conditions, temperature cycling experiments were performed between 323 and $503 \mathrm{~K}$ with fast $(10 \mathrm{~K} / \mathrm{min})$ and slow ramps $(2 \mathrm{~K} / \mathrm{min})$ and intermediate holds of $10-30 \mathrm{~min}$ at $503 \mathrm{~K}$ for XRD measurements. The second cycle of one experiment with $\operatorname{actX} / \mathrm{RuO}_{2}$ is shown in figure 7. The ignition temperature was always found to be higher for the first cycle (here $418 \mathrm{~K}$, not shown) and almost constant for subsequent cycles $(\sim 410 \mathrm{~K})$. For the act $/ \mathrm{Ru}$ samples, the ignition temperature was always significantly lower $(\sim 380 \mathrm{~K})$. In contrast to the sharp ignition events, the decrease of activity during cooling is more complex, suggesting the convolution of two or more partial extinction events. In a second type of experiment, the temperature was increased stepwise with one hour holds (every $10 \mathrm{~K}$ between 343 and $373 \mathrm{~K}$, every $5 \mathrm{~K}$ between 373 and $433 \mathrm{~K}$ ). Ignition occurred while increasing the temperature from 433 to $438 \mathrm{~K}$. The results are summarized in an Arrhenius plot in figure 8 together with a comparison of former results from the literature. Despite the differences in the temperature profiles used, the actX/RuO $\mathrm{R}_{2}$ samples consistently yield apparent activation energies of $(110 \ldots 105) \pm 5 \mathrm{~kJ} / \mathrm{mol}$. In contrast, the actY/Ru samples exhibit lower apparent activation energies of $(82 \ldots 102) \pm 5 \mathrm{~kJ} / \mathrm{mol}$ and approximately two to up to fifty times higher $\mathrm{CO}_{2}$ formation rates at $403 \mathrm{~K}$, both with a greater variation than the oxidized samples. The activity rise at higher temperatures of the most active actY/Ru and the actX/ $\mathrm{RuO}_{2}$ sample in the Arrhenius plot (fig. 8) is due to the starting ignition. Careful analysis of the temperature related shifts of the $\mathrm{BN} 002$ peak could be used to measure internally the temperature of the catalyst. It turns out that before reaching the ignition state the temperature in the illuminated area follows the temperature of the controlling

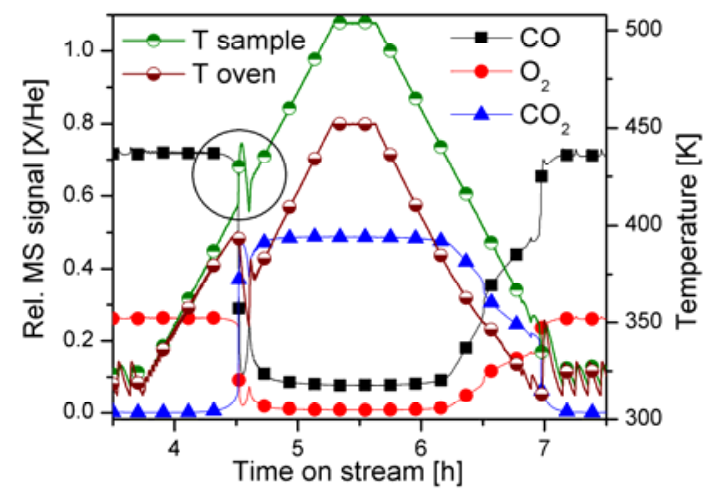

Fig. 7: (Color online) Temperature cycle experiment on actX/ $\mathrm{RuO}_{2}$ with slow ramps $(2 \mathrm{~K} / \mathrm{min})$ in a stoichiometric $\left(\mathrm{CO}: \mathrm{O}_{2} 10: 5\right)$ feed. The abrupt temperature rise due to ignition is marked by a circle. The oscillations seen at low temperature are artefacts, caused by the slow response of the oven to the PID control.

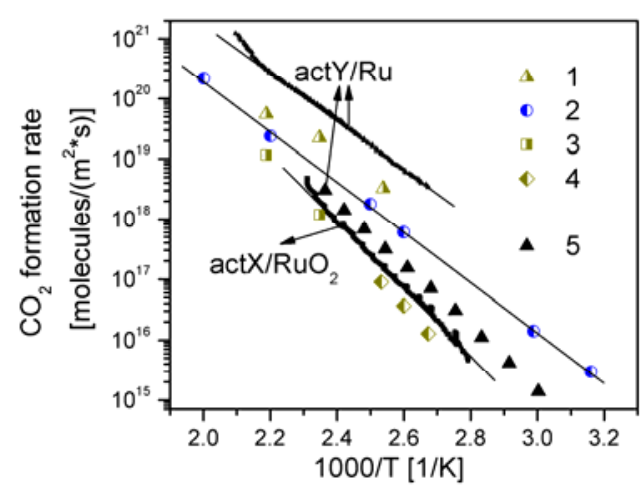

Fig. 8: (Color online) Comparison of the $\mathrm{CO}_{2}$ formation rates over $\operatorname{actX} / \mathrm{RuO}_{2}$ and actY/Ru, CO:O $2: 1$ (related to surface area of the originally re-oxidized $\mathrm{RuO}_{2}$ sample, $1 \mathrm{~m}^{2} / \mathrm{g}$ [23]) with rates obtained in the literature: 1) metallic, polycrystalline $\mathrm{Ru}, \mathrm{CO}: \mathrm{O}_{2} 1: 2$ [24], 2) oxygenated $\mathrm{Ru}(0001)$, ascribed as chemisorbed (1x1) oxygen layer (1 ML) in [3], $\mathrm{CO}: \mathrm{O}_{2} 2: 1,3$ ) oxidized $\mathrm{RuO}_{2}$, $\mathrm{CO}: \mathrm{O}_{2}$ 1:2 [24], 4) supported $\mathrm{RuO}_{2}$ nanoparticles, $\mathrm{CO}: \mathrm{O}_{2} 1: 2$ [25], and 5) for comparison of the rate variation the lowest $\mathrm{CO}_{2}$ formation rate for actY/Ru obtained in this work, $\mathrm{CO}: \mathrm{O}_{2} 2: 1$ 
thermocouple $\mathrm{TC} 1$ at the edge of the catalyst bed (fig. 1) within a few Kelvin. Directly after ignition the temperature rises more than $70 \mathrm{~K}$ above the temperature of thermocouple TC1. In the ignited state of the actY/Ru catalyst the temperature is 50 to $55 \pm 3 \mathrm{~K}$ higher than that at TC1. It should be mentioned here that the whole temperature gradient is not necessarily located inside the catalyst bed but more likely in the surrounding ceramic-crucible.

Due to the very long induction times the measurements of the $\mathrm{RuO}_{2}$ activation under net-oxidizing conditions similar to the first experiment in the quartz tube reactor are under way and shall be the content of a forthcoming paper.

\subsection{SEM}

While the as-received $\mathrm{RuO}_{2}$ powder mainly consists of small particles with undefined shape (not shown), the calcined $\mathrm{RuO}_{2}$ exhibits crystals in the micrometer range but also very small particles (fig. 9). From the SEM pictures the total surface area of these small particles is estimated to be lower than $5 \%$ of the large crystal surface area. These large crystals exhibit smooth, often stepped surfaces; however, they are showing sometimes round holes. The usual habit is irregular octagonal in cross section, thus exhibiting the lateral $\{110\},\{100\}$, and apical $\{101\},\{111\}$ facets (the curly brackets are used for the set of equivalent facets due to symmetry). After activation to actX/ $\mathrm{RuO}_{2}$ the large particles typically look like the one shown in figure 10a. All apical $\{101\}$ and $\{111\}$ facets become rough with smoother areas around the edges of two facets while nearly all of the lateral $\{110\}$ and $\{100\}$ surfaces remain smooth. This leads to kinds of habit: 1) only all apical facets are rough (fig. 10a), 2) - seldom - all apical facets and one lateral surface are rough (fig. 10b) and 3) - very seldom more than one lateral surface are rough. Partly rough surfaces were not found. Typical EDX spectra of the rough and flat surfaces are shown in figure 10c. The flat surfaces

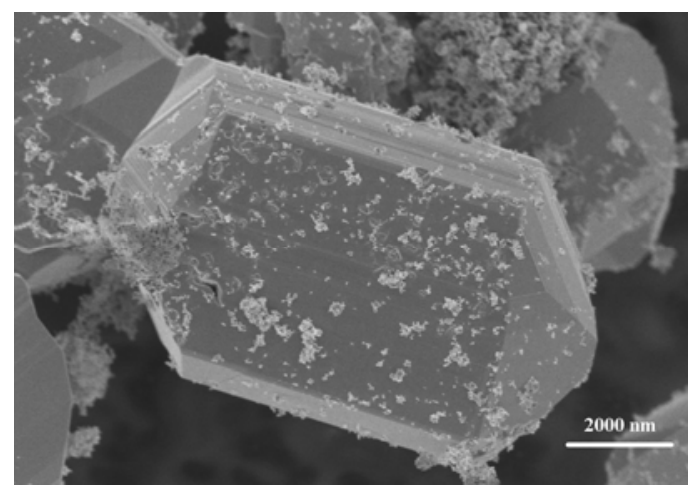

Fig. 9: $\mathrm{SEM}$ picture of a typical $\mathrm{RuO}_{2}$ crystal after calcination exhibiting the lateral $\{110\},\{100\}$, and apical $\{101\},\{111\}$ facets (the curly brackets are used for the family of symmetry-equivalent facets). Besides the large crystals, very small particles are always observed. are fully oxidized as the calcined $\mathrm{RuO}_{2}$. The apical facets are more heavily reduced than the lateral, rough surface.

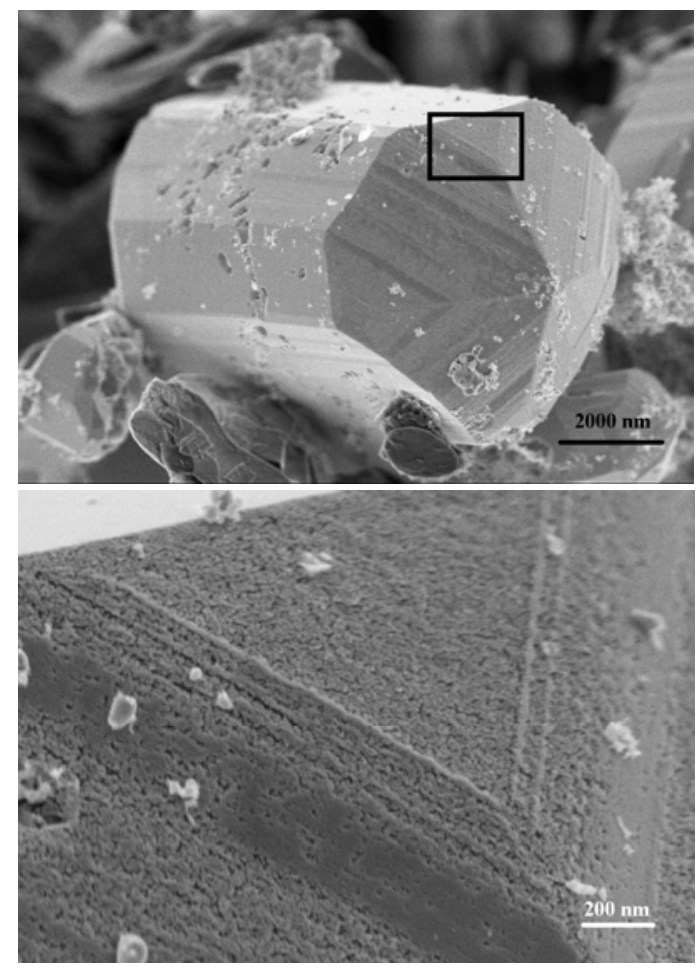

Fig. 10a: A typical particle after activation to $\operatorname{actX} / \mathrm{RuO}_{2}$ : In the magnified picture (right hand) clearly the roughening of the $\{111\}$ and $\{101\}$ facets are to be seen.

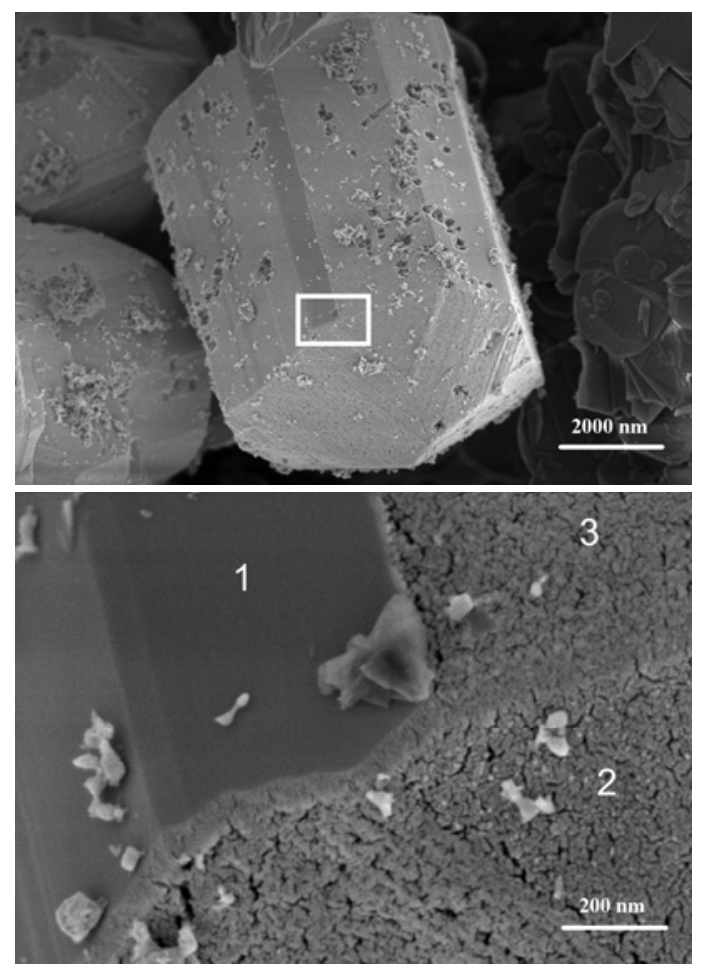

Fig. 10b: One of the particles rarely observed with one rough lateral facet to be seen in the magnified micrograph. The corresponding EDX spectra for the numbered areas are shown in fig. 10c. The holes in the flat surfaces are still round like those in the calcined sample. 


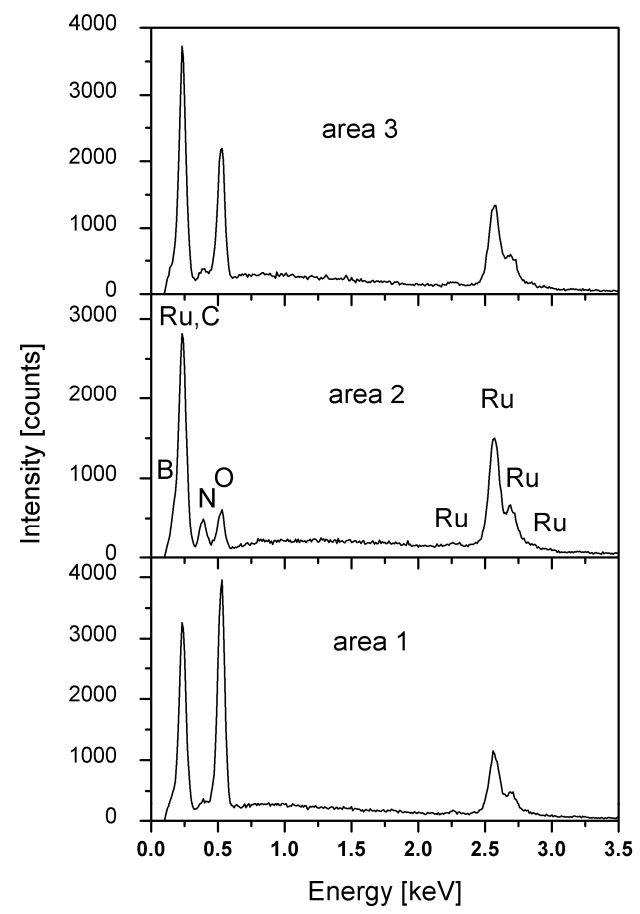

Fig. 10c: EDX spectra with $5 \mathrm{kV}$ accelerating voltage in the marked areas of Fig. 10b.

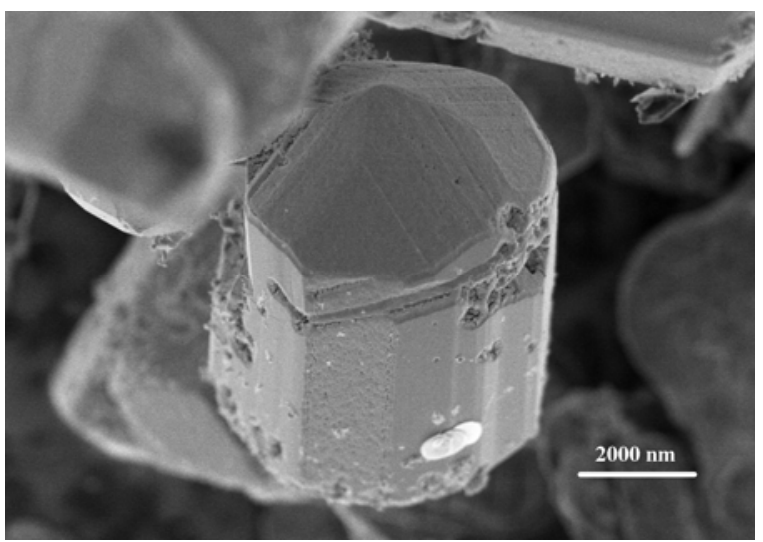

Fig. 11: A particle directly after reduction exhibiting still only one roughened lateral facet in addition to the roughened apical facets. Cracks and first star-shaped holes are to be found.

Figure 11 shows a particle from a sample directly after reduction to actY/Ru. The differences to the particle in figure $10 \mathrm{~b}$ are small but obvious: large cracks and some star-shaped holes can be found. These cracks and starshaped holes are probably due to the volume decrease during reduction of the sample.

After reducing and cycling several hours up to $503 \mathrm{~K}$ in the $\mathrm{CO}: \mathrm{O}_{2}$ 10:5 reaction feed, the originally $\mathrm{RuO}_{2}$ crystals become very rough and sponge-like, exhibiting deep star-shaped holes and crater-like cracks (fig. 12). Within the SEM resolution the largest "smooth" areas are in the range of $100 \mathrm{~nm}$.
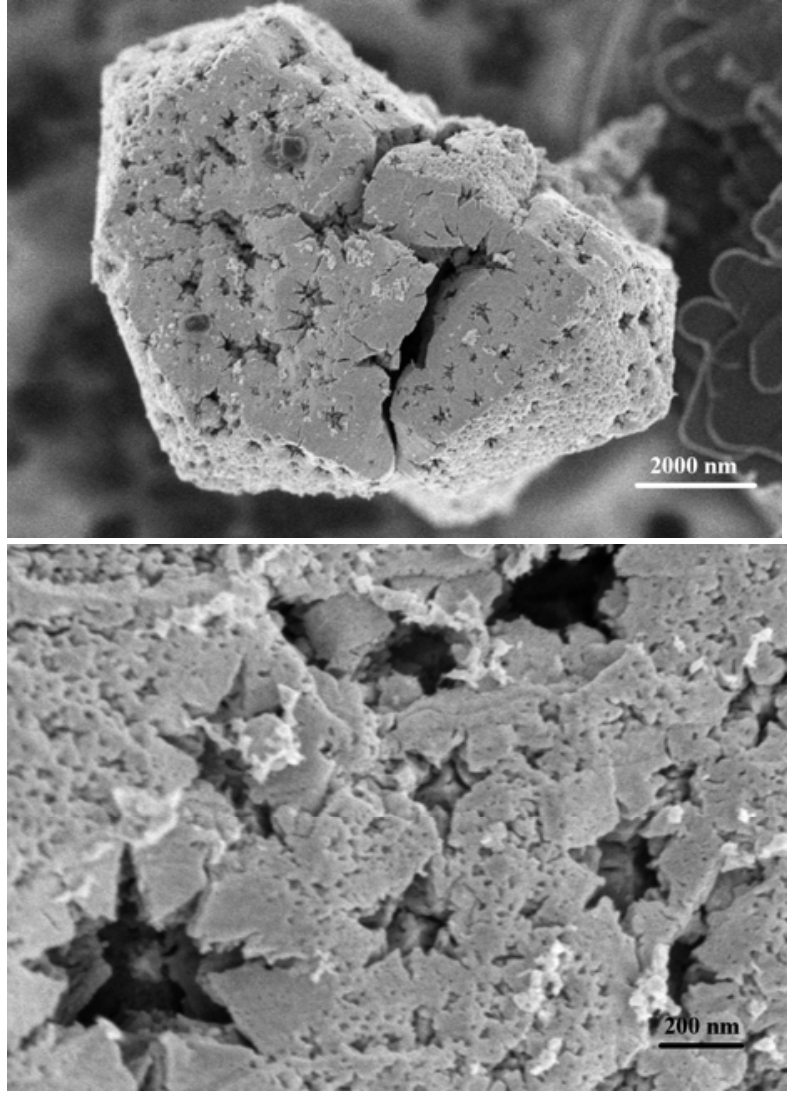

Fig. 12: SEM micrographs of a reduced particle. The actY/Ru sample was several hours in a $\left(\mathrm{CO}: \mathrm{O}_{2}\right.$ 10:5) stream during temperature cycles.

\subsection{SPEM and microspot XPS}

In order to examine the homogeneity of the surface state of oxygenated $\mathrm{Ru}(0001)$ as function of preparation temperature, a clean $\mathrm{Ru}(0001)$ surface was exposed to $10^{5} \mathrm{~L} \mathrm{O}_{2}$ at different sample temperatures. According to previous experiments this treatment will yield a saturated chemisorption layer of oxygen over the whole temperature range from RT to $775 \mathrm{~K}$ [26]. It should be noted here that this saturated chemisorption layer is not necessarily the chemisorbed $(1 \mathrm{x} 1)$ oxygen layer $(1 \mathrm{ML})$ proposed as the active catalytic state by Peden and Goodman [3] because the $(1 \mathrm{x} 1)$ LEED patterns do not yield information on the oxygen content of deeper layers. The lateral distribution was monitored by spectroimaging in the $\mathrm{Ru} 3 \mathrm{~d}_{5 / 2}$ region and by performing microspot XPS within different areas of the images (Fig. 13). Whereas the corresponding LEED image shows the characteristic sharp $(1 \times 1)$ pattern (not shown here), the SPEM image of the first preparation at $\mathrm{T}_{\text {prep }}=475 \mathrm{~K}$ (topmost panel) already exhibits a spatial heterogeneity as can be seen in the differences of intensity. This is reflected by the microspot XP spectra. The plot on the left shows the typical spectrum of an adsorbed oxygen state consisting of the bulk metallic intensity $(280.1 \mathrm{eV})$ and components correlated to $\mathrm{Ru}$ atoms of the topmost layer coordinating with two and three oxygen atoms, $\mathrm{Ru}(\mathrm{I})$ $2 \mathrm{O}$ and $\mathrm{Ru}(\mathrm{I})-3 \mathrm{O}$, respectively. A surface solely exhibiting 


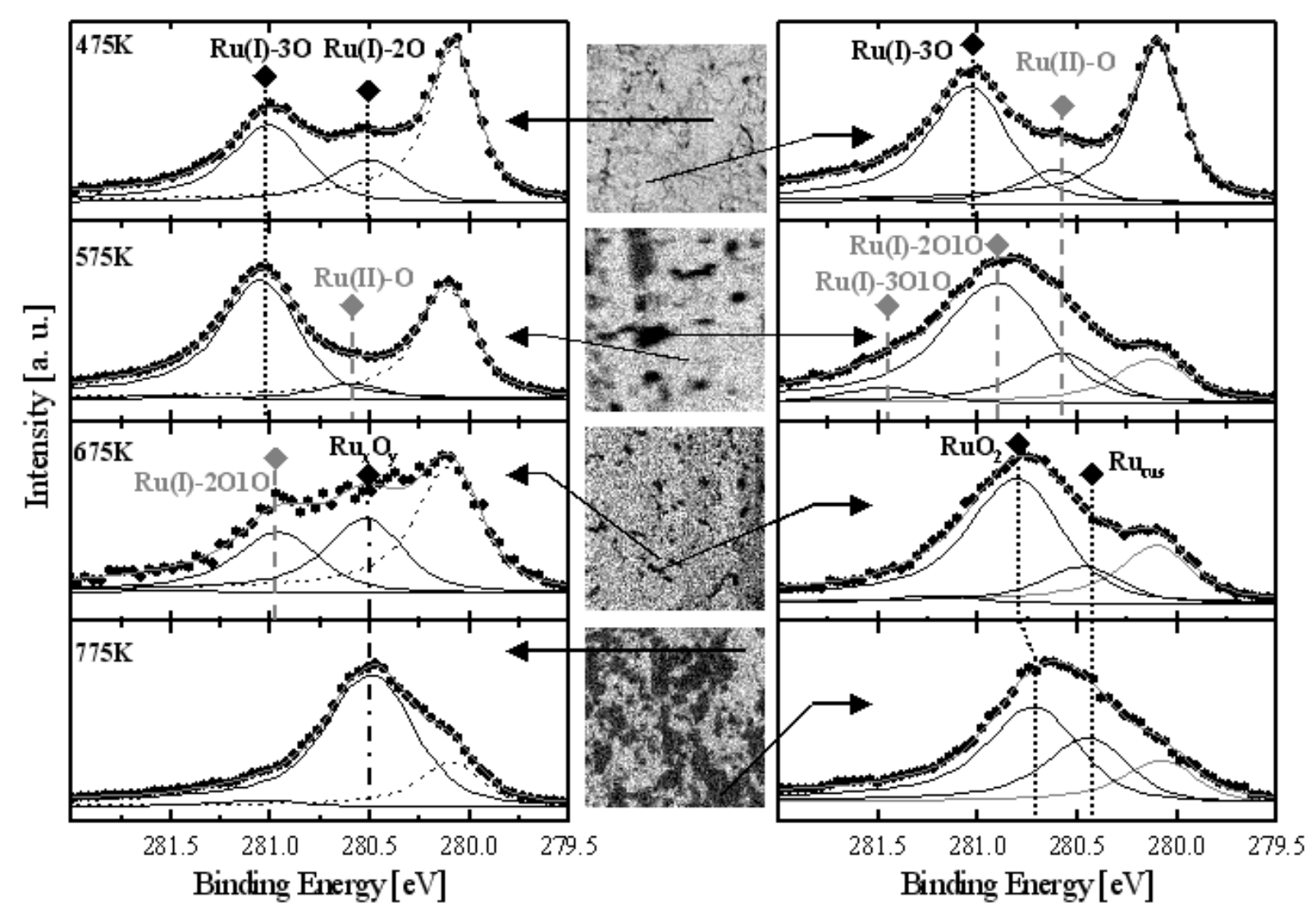

Fig. 13: SPEM images and microspot XPS of a $\mathrm{Ru}(0001)$ surface exposed to $10^{5} \mathrm{~L}$ of molecular oxygen at different $\mathrm{T}_{\text {Prep }}$; middle panel: $64 \times 64 \mu \mathrm{m} \mathrm{Ru} 3 \mathrm{~d}_{5 / 2}$ images recorded with a resolution of $0.5 \mu \mathrm{m}$; left and right panel: spectra taken in different areas of the images marked by arrows; peak positions and nomenclature indicated by vertical lines are explained in the text; lines labelled in the text as $\mathrm{Ru}(\mathrm{I})-2 \mathrm{O}_{\text {ad }} 1 \mathrm{O}_{\text {sub }}$ and $\mathrm{Ru}(\mathrm{I})-3 \mathrm{O}_{\text {ad }} 1 \mathrm{O}_{\text {sub }}$ are shortened to $\mathrm{Ru}(\mathrm{I})-2 \mathrm{O} 1 \mathrm{O}$ and $\mathrm{Ru}(\mathrm{I})-3 \mathrm{O} 1 \mathrm{O}$ in the figure.

$\mathrm{Ru}(\mathrm{I})-3 \mathrm{O}$ would be Peden and Goodman's chemisorbed (1x1) oxygen layer (1 ML).

The coexistence of the latter components at 280.48 and $281.03 \mathrm{eV}$ indicates that in this area the $(1 \times 1)$ layer is not completely saturated. In contrast, the image on the right exhibits an intense $\mathrm{Ru}(\mathrm{I})-3 \mathrm{O}$ component and an additional component at $\sim 280.55 \mathrm{eV}$. This peak was assigned to $\mathrm{Ru}$ atoms of the second layer coordinated with one (subsurface) oxygen atom [17], labelled Ru(II)-O. Obviously, in this region of the surface the oxygen incorporation has already started.

Oxygen exposure at higher sample temperatures, $\mathrm{T}_{\text {Prep }}=575 \mathrm{~K}$, leads to a more pronounced contrast in the SPEM images. The components of the spectrum recorded in the bright area indicate a saturated chemisorption layer, $\mathrm{Ru}(\mathrm{I})-3 \mathrm{O}$ with a small contribution of incorporated oxygen, $\mathrm{Ru}(\mathrm{II})-\mathrm{O}$. The spectrum taken in the dark area exhibits the typical spectrum correlated with an advanced formation of the TSO state. Next to the bulk peak, the spectrum consists of components at 280.9 and $281.45 \mathrm{eV}$, representing $\mathrm{Ru}$ atoms coordinated with two and three oxygen atoms on and one additional oxygen atom below the surface (labelled $\mathrm{Ru}(\mathrm{I})-2 \mathrm{O}_{\mathrm{ad}} \mathrm{O}_{\text {sub }}$ and $\mathrm{Ru}(\mathrm{I})-3 \mathrm{O}_{\mathrm{ad}} \mathrm{O}_{\text {sub }}$ ) [17]. The latter $\mathrm{Ru}$ species is characteristic for the O-Ru-O trilayer proposed by Reuter et al. [14], i.e. transient surface oxide (TSO). The
LEED image corresponding to this preparation still exhibits a $(1 \times 1)$ pattern, yet with a brighter background which indicates a distortion of the $\mathrm{Ru}$ lattice due to the additional oxygen atoms below the surface layer.

With further increase of $\mathrm{T}_{\text {Prep }}$ to $675 \mathrm{~K}$ the contrast in the SPEM image becomes less pronounced. However, the overall intensity is decreasing. The XP spectra recorded in the bright (left) and dark area (right) of the image differ considerably. The spectrum of the bright area consists of the bulk component, a strong component at $280.48 \mathrm{eV}$ and a weaker $\mathrm{Ru}(\mathrm{I})-2 \mathrm{O}_{\mathrm{ad}} \mathrm{O}_{\text {sub }}$ peak with a slightly shifted binding energy. The shift of the former indicates a restructuring of the deeper $\mathrm{Ru}$ layers due to incorporated oxygen atoms. Interestingly, no $\mathrm{Ru}(\mathrm{I})-3 \mathrm{O}_{\text {ad }} \mathrm{O}_{\text {sub }}$ component is found in this spectrum. This can be explained by the low thermal stability of this state, which has been previously shown to decay at temperatures $\geq 670 \mathrm{~K}$ [26]. The changes in the spectrum recorded in the dark area are even more distinct. Here, two peaks at 280.8 and $280.45 \mathrm{eV}$ are observed which are assigned to a yet not well-ordered $\mathrm{RuO}_{2}(110)$ oxide and $\mathrm{Ru}$ atoms of the oxide surface which are under-coordinated with oxygen atoms $\left(\mathrm{Ru}_{\mathrm{cus}}\right)$ [27]. In the corresponding LEED image for this preparation a further increase of the bright background is observed. 
The last increase of $\mathrm{T}_{\text {Prep }}$ to $775 \mathrm{~K}$ yielded a very heterogeneous surface composition as reflected by the large bright and dark areas. The spectrum of the bright area is dominated by an intense component at $280.48 \mathrm{eV}$. Due to its higher intensity compared to the bulk peak, it was assigned to a disordered $\mathrm{Ru}_{\mathrm{x}} \mathrm{O}_{\mathrm{y}}$ state reflecting the increasing amount of incorporated oxygen atoms. The spectrum of the dark area shows the typical peaks representative for a well ordered $\mathrm{RuO}_{2}(110)$ surface as found in the literature [27]. Here, additional LEED spots are observed, indicating the onset of oxidation.

An essential prerequisite for the build-up of subsurface oxygen (which is synonymous with the formation of a transient surface oxide (TSO)) or even for a stoichiometric oxide surface seems to be the formation of a saturated $(1 \times 1)$ adsorption state. Under these conditions a LEED $(1 \times 1)$ pattern is observed except for very high temperatures near the onset of oxygen desorption. Here, additional spots are found representing the onset of $\mathrm{RuO}_{2}$ formation.

In summary, the results presented in Fig. 13 illustrate that even under conditions where, partly due to the application of an averaging method, one can expect a well ordered surface state, the more detailed view provides evidence for a quite heterogeneous catalyst surface.

\section{Discussion}

In the following parts we will discuss the surface and bulk state of the Ruthenium catalyst in the context of their homogeneity and catalytic activity. The phenomenon of the ignition/extinction - oscillation behavior will be discussed in the last part.

\subsection{Surface state of the catalyst}

In a very early paper Peden and Goodman investigated the catalytic activity of $\mathrm{Ru}(0001)$ in the CO-oxidation at pressures around $20 \mathrm{mbar}$ [3]. They used AES for the oxygen quantification subsequent to the reaction and found a coverage of $\sim 1$ monolayer oxygen to be most active. In the context of our SPEM results and a recent paper monitoring with in-situ XPS the surface state of $\mathrm{Ru}(0001)$ during CO-oxidation [17] it might be useful to come back to the experimental details of Peden and Goodmans early work. They measured under steady state conditions (16 Torr $\mathrm{CO}$ and 8 Torr $\mathrm{O}_{2}$ ) the activity of a clean $\mathrm{Ru}(0001)$ single crystal at fixed temperatures in the range of 350-625 K. The quantification of the remaining oxygen on the $\mathrm{Ru}(0001)$ surface was undertaken after flashing the sample to $600 \mathrm{~K}$ to remove adsorbed $\mathrm{CO}$ since it was known that $\mathrm{CO}$ decomposes under influence of an electron beam.

At first we analyze the surface state after simply oxidizing a clean $\mathrm{Ru}(0001)$ single crystal in oxygen without $\mathrm{CO}$ at different temperatures. The outcome of our SPEM experiments is that even under ideal oxidizing conditions a strong inhomogeneity of the oxygen surface state occurs. While at lower temperatures the chemisorbed (1x1) oxygen layer (1 ML) is prevalent, at higher temperatures the chemisorbed (1x1) oxygen layer (1 ML) decays and $\mathrm{RuO}_{2}$ develops, at all temperatures accompanied by subsurface oxygen and transient surface oxide (subO/TSO). These results put some first doubts on the homogeneity of the surface state during Peden and Goodmans catalytic experiments. If we include now additionally $\mathrm{CO}$, i.e. a real reactants mixture, the results of the mentioned previous paper [17] are very interesting: In a 1:1 feed of $\mathrm{CO}$ and $\mathrm{O}_{2}$ at a pressure of $0.1 \mathrm{mbar}$ the temperature was ramped with $2 \mathrm{~K} / \mathrm{min}$ from $\mathrm{RT}$ to $590 \mathrm{~K}$. In the temperature range of $430-510 \mathrm{~K}$ there exists mainly subO/TSO but there might be also very little chemisorbed (1x1) oxygen without subsurface oxygen. This questions the developing of the $(1 \mathrm{x} 1)$ chemisorbed oxygen (1ML) without subsurface oxygen during Peden and Goodman's catalytic experiments.

Although we can not fully rule out the contribution of the chemisorbed $(1 \mathrm{x} 1)$ oxygen layer $(1 \mathrm{ML})$ to the reaction at low temperature, at elevated temperature at least the occurrence of subO/TSO must be taken into account.

A similar argument holds for the case of $\mathrm{RuO}_{2}$ : additional to our SPEM results, the coexistence of TSO and $\mathrm{RuO}_{2}$ grown at elevated temperatures is nicely supported by an early work of Kim et al. [28] using LEED for a study of oxygenated $\mathrm{Ru}(0001)$ after dosage of $6 \times 10^{6} \mathrm{~L}$ oxygen at $600 \mathrm{~K}$. Only very high dosages of $1 \times 10^{7}$ Langmuir at still higher temperatures, $700 \mathrm{~K}$, should lead to a surface almost completely covered by $\mathrm{RuO}_{2}$ (judged by a rather integral method, LEED) [29,30]. Since Knapp et al. [11] reported $750 \mathrm{~K}$ as preparation temperature for the inactive $\mathrm{RuO}_{2}(100)-\mathrm{c}(2 \times 2)$ surface there exists, if ever, only a small preparation window for active $\mathrm{RuO}_{2}$ without subO/TSO.

Since it is obviously very ambiguous, if not impossible, to grow solely one single surface oxygen-phase on $\mathrm{Ru}(0001)$ except for $\mathrm{RuO}_{2}$ at very high temperatures and oxygen dosages, it is interesting to analyze catalytic experiments with fully oxidized $\mathrm{RuO}_{2}$. Several papers dealt with re-oxidized Ru particles as "core-shell" catalysts with a thin $\mathrm{RuO}_{2}$ layer on a $\mathrm{Ru}$ metal core $[10,24,25]$. These catalysts should exhibit the highest formation rates of $\mathrm{CO}_{2}$ [10]. Keeping the aforementioned argument in mind and that the re-oxidation occurs at mild temperatures (up to $573 \mathrm{~K}$ ), these facts cast doubt on the picture of a solely grown $\mathrm{RuO}_{2}$ layer being simply over-idealized and hence highly unlikely.

In two DFT studies [31] the thermodynamics of the oxygen/ruthenium system was investigated. It turns out that under all conditions at $300 \mathrm{~K}$ - even in $\mathrm{UHV}-\mathrm{RuO}_{2}$ is the stable phase. Therefore all phases observed in our and previous studies except $\mathrm{RuO}_{2}$ should be considered as metastable. Hence in this dynamic system with kinetic hindrance a mixture of all phases is possible. [32] 


\section{2. $\mathrm{RuO}_{2}$ as bulk phase}

The different induction time of the catalyst in the packed bed reactor and the in-situ XRD cell found in the present study may be due to the different re-oxidation regimes of the pristine $\mathrm{RuO}_{2}$. The same argument holds for the immediate activity of polycrystalline pre-calcined $\mathrm{RuO}_{2}$ in Narkhede et al. [24] because they used a low precalcination temperature of $573 \mathrm{~K}$. Since our very long induction times are not reported in the literature we will discuss them in the context of deactivation.

In the literature the deactivation particularly of oxidized samples is explained with an inactive state of the $\{110\}$ and $\{100\}$ facets, namely the reconstructed $\mathrm{RuO}_{2}(100)-\mathrm{c}(2 \times 2)$ surface $[8,10,11]$. The occurrence of this reconstructed $\mathrm{RuO}_{2}(100)-\mathrm{c}(2 \times 2)$ surface is nicely supported by our experiments: First, the irregular octagonal cross section habit of the calcined $\mathrm{RuO}_{2}$ crystals in contrast to the obelisk-like habit shown in the literature [24] points to an equilibration of the (110) and (100) surface energies. This would be the case for a $\mathrm{RuO}_{2}(100)-\mathrm{c}(2 \times 2)$ microfacetted (110) surface. Second, the inertness of the lateral surfaces to reduction compared with the apical surfaces can be explained by the reason for the inactivity of the $\mathrm{RuO}_{2}(100)$-c $(2 \times 2)$ surface in the CO-oxidation: the very low sticking coefficient of CO [11]. Anyhow, the initial inactivity and very long induction period of calcined $\mathrm{RuO}_{2}$ in our experiments can only be partly understood by this argument.

Every $\mathrm{RuO}_{2}$ crystalline particle should additionally exhibit $\{101\}$ facets, which are $(1 \times 2)$ reconstructed as found using LEED by Kim et al. [33]. The surface energy for the non-reconstructed (101) surface has been calculated to be $76 \mathrm{meV}^{-2}$, i.e. the second lowest after the (110) surface with $71 \mathrm{meV} \AA^{-2}$ [10]. The rutile $\mathrm{TiO}_{2}(101)$ surface in grown films and single crystals also possess a $(1 \times 2)$ reconstruction [34,35]. In analogy to a model for this rutile $\mathrm{TiO}_{2}(101)-(1 \times 2)$ surface $[35,36]$ the $\mathrm{RuO}_{2}(101)-(1 \times 2)$ surface should also exhibit two kinds of five-fold coordinated $\mathrm{Ru}$ atoms: cus-sites in a zig-zag configuration as well as $\mathrm{Ru}$ atoms with a $\mathrm{Ru}=\mathrm{O}$ double bond. In their study Kim et al. [33] used a $\mathrm{RuO}_{2}$ single crystal grown by vapor deposition under similar conditions to our pre-calcination. With this single crystal they found that the $(1 \times 2)-(101)$ surface should be as active in the $\mathrm{CO}$ oxidation as the $\mathrm{RuO}_{2}\{110\}$ and $\{100\}$ facets. Our SEM results show that the precalcined $\mathrm{RuO}_{2}$ crystals indeed exhibit $\{101\}$ facets, which however must be completely inactive in $\mathrm{CO}$ oxidation. This obvious contradiction can not fully be resolved here; there may be two possibilities: First, the experimental conditions in the study of Kim et al. [33], especially the long-time annealing in $5 \times 10^{-6}$ mbar oxygen at $800 \mathrm{~K}$ for $2 \mathrm{~h}$, lead to a similar reduction as found in our study. Second, the $(1 \mathrm{x} 2)$ reconstructed (101) surfaces exhibits indeed activity but, however, very low. If the $(1 \times 2)$ reconstructed (101) surface really exhibit cus-sites, from this second possibility follows that cus-sites exhibit very low activity and hence do also the (110) and (100) surfaces. Due to the fact that Over et al.
[37] found pits in a flat (110)- $\mathrm{RuO}_{2}$ sample after mild reduction and annealing at $600 \mathrm{~K}$ in vacuum and these pits might represent the beginning reduction to subO/TSO the first given explanation is more likely.

The roughened and slightly reduced $\{101\}$ and $\{111\}$ facets observed after activation to actX/RuO $\mathrm{R}_{2}$ suggest a correlation of the rising activity with the surface modification labeled actX. Although we can not reveal the surface state $\mathrm{X}$ with our methods the following scenario seems to be very likely: Under very low CO conversion the $\{111\}$ and $\{101\}$ facets are slowly reduced to subO/TSO. Whether some $\mathrm{RuO}_{2}$ islands remain we can not decide but the reduction to Ru-metal with a remaining chemisorbed (1x1) oxygen layer (1ML), but without any subsurface oxygen seems rather unlikely to us. Note that the bulk is still $\mathrm{RuO}_{2}$. Thus we assign the surface modification $\mathrm{X}$ to subO/TSO, probably accompanied by some $\mathrm{RuO}_{2}$ islands (active subO/TSO- $\mathrm{RuO}_{2} / \mathrm{RuO}_{2}$ ).

For the active subO/TSO- $\mathrm{RuO}_{2} / \mathrm{RuO}_{2}$ we found apparent activation energies of $(110 \ldots 115) \pm 5 \mathrm{~kJ} / \mathrm{mol}$, much higher than the experimentally observed activation barrier of $86 \mathrm{~kJ} / \mathrm{mol}$ on the polycrystalline $\mathrm{RuO}_{2}$ sample in [24]. The polycrystalline $\mathrm{RuO}_{2}$ sample in [24] mainly exhibited $\{110\}$ and $\{111\}$ facets. Since in our case the $\{100\}$ and $\{110\}$ surfaces are likely spectators, the observed turnover rates are surprisingly high. Hence the presence of active and inactive facets illustrates the problem of the TOFconcept. Since usually TOFs are calculated by dividing the rate of a reaction (related to surface area and time) by the number of active sites per surface area this problem is twofold: First, as long as one only refers to surface area in our case the rates are at least a factor of three too low (note that the $\{100\}$ and $\{110\}$ surfaces are likely spectators). Second, the inhomogeneity of the oxygenated Ru-surfaces observed in [17] or in our SPEM and SEM results shows that without the knowledge of the kind and hence the number of active centers, TOFs are not necessarily useful in comparing different catalysts.

\subsection{Ru metal as bulk phase}

The fact that the active subO/TSO- $\mathrm{RuO}_{2} / \mathrm{RuO}_{2}$ samples are not reduced by a strongly reducing feed (14:1) at $503 \mathrm{~K}$ but do reduce at higher temperature $(543 \mathrm{~K})$ revealed the bulk reduction of $\mathrm{RuO}_{2}$ is a strongly temperature dependent process with a high activation energy. Two main reduction scenarios are found, first the reduction through the apical surfaces and second the reduction along inhomogeneities of the $\mathrm{RuO}_{2}$ crystals. The different crystallite sizes obtained by SEM and XRD point to well shaped but not single crystalline $\mathrm{RuO}_{2}$ particles. These defects seemed to be also responsible for the reduction. The oxygen transport in oxygenated Ruthenium systems is rather poorly investigated. Blume et al. [38] found two channels of oxygen incorporation into $\mathrm{Ru}$, the first is defect-mediated and highly efficient, while the second is attributed to incorporation of oxygen from the $(1 \times 1)$ chemisorbed oxygen layer. 
Within the principle of microscopic reversibility these channels should be also responsible for the reduction of $\mathrm{RuO}_{2}$ and subO/TSO-systems. Furthermore, if a mildly reduced (110) $-\mathrm{RuO}_{2}$ surface (i.e. the bridging oxygen atoms are replaced by $\mathrm{CO}$ ) will be annealed at $600 \mathrm{~K}$ pits of $\mathrm{Ru}$ - metal or $\mathrm{Ru}$ with subO/TSO are formed and the (110)$\mathrm{RuO}_{2}$ surface is re-oxidized as observed by STM [37]. This means that the (110)- $\mathrm{RuO}_{2}$ surface will be re-oxidized on the cost of more strongly reduced areas. Thus the oxygen around defects has a high chemical potential to re-oxidize the bridging oxygen atoms making it a promising candidate for either incorporation into the bulk (re-oxidation of the bulk) or the oxidation of $\mathrm{CO}$ [39].

Following part one and two of this discussion the surface state of the reduced sample with $\mathrm{Ru}$ metal as bulk phase could additionally to $\mathrm{RuO}_{2}$ and subO/TSO exhibit surface areas of the chemisorbed $(1 \mathrm{x} 1)$ oxygen layer. Although $\mathrm{RuO}_{2}$ is very stable in a reductive atmosphere [17], after long term reduction we could expect nearly no $\mathrm{RuO}_{2}$. Accordingly, the active state of $\mathrm{Ru}$ metal (actY/Ru) should be called subO/TSO - $(1 \times 1) \mathrm{O}-\left(\mathrm{RuO}_{2}\right) / \mathrm{Ru}$.

While the higher activity and lower ignition temperatures might be related to the higher surface area the lower and fluctuating apparent activation energies of $(82 \ldots 102) \pm 5 \mathrm{~kJ} / \mathrm{mol}$ indicate not only the difference to the active subO/TSO $-\mathrm{RuO}_{2} / \mathrm{RuO}_{2}$ state but also a significantly dynamic nature of the surface. Vogel and Alonso-Vante [15] found agglomeration and "growth to more perfect cluster morphology" (p. 399 in [15]) of nanocrystalline Ru metal during $\mathrm{CO}$ oxidation in a stoichiometric feed. If defects play a significant role in the $\mathrm{CO}$ oxidation this agglomeration will lead to lower conversion not only due to lower surface area but also due to fewer defects.

The high $\mathrm{CO}_{2}$ formation rate of our reduced subO/TSO-(1x1)O- $\left(\mathrm{RuO}_{2}\right) / \mathrm{Ru}$ samples could also originate from a high defect density as suggested by XRD: The broad XRD $\mathrm{Ru} 011$ reflection points to either very small crystallites $(8 \mathrm{~nm})$ or somehow otherwise distorted particles.

\subsection{Ignition/extinction behavior and induction period}

While in an early paper about the CO oxidation over supported $\mathrm{Ru} / \mathrm{SiO}_{2}$ catalysts Kiss and Gonzalez [40] reported steady-state oscillations in a reducing feed, Assmann et al. [10] found oscillations in a stoichiometric feed also with supported $\mathrm{Ru} / \mathrm{SiO}_{2}$ catalysts (both under isothermal conditions). In the present paper pronounced oscillation in the fixed-bed reactor under net oxidizing quasi-isothermal conditions, as well as ignition/extinction behavior during temperature ramping under all applied feed conditions were observed. Interestingly our oscillations as well as the oscillations observed by Assmann et al. [10] occur around conversion of $80 \%$ of the minor feed component.

Generally, an ignition/extinction behavior could have three simple reasons, the first is induced by external heat and mass transfer, the second is due to two states of the system with different activity and the third includes a slow rate limiting step. For an overview the review of Imbihl and Ertl [1] is very useful.

According to Onken and Wicke [41] catalytic measurements of the high activity state are possible with a high gas velocity in an adiabatic packed bed reactor. These conditions could lead to the high activity state without switching back. These measurements would help to understand the highly active state or to reveal transport limitations as a reason for the ignition/extinction behavior. Although such experiments may be very useful, it was not our intent to follow this line in this study.

In principle, it should be possible to establish a model for our observed oscillations under net oxidizing quasiisothermal conditions based on different activities of the subsurface oxygen (TSO) and $\mathrm{RuO}_{2}$. Since the sample is very likely still bulk $\mathrm{RuO}_{2}$, we can exclude the chemisorbed (1x1) oxygen layer (1ML on Ru metal). However, as we have no catalytic data of single phase subO/TSO or $\mathrm{RuO}_{2}$, this is highly speculative. It should be mentioned here that the subO/TSO itself could consist of different activity states - leading to the same oscillatory behavior.

The high frequency oscillation in the packed-bed reactor could reveal a third pseudo steady state with intermediate activity. The fast switching and the quantity of the $\mathrm{CO}$ converted $\left(\approx\right.$ one $\mathrm{CO}$ molecule per $\mathrm{RuO}_{2}$ surface unit cell) point to a coverage equilibration. In a recent paper Reuter and Scheffler have shown by first-principles kinetic Monte Carlo simulations that the highest TOFs at $\mathrm{RuO}_{2}(110)$ surfaces are reached when the adsorption state of the surface is disordered and very dynamic [42]. This can be an explanation for the high frequency oscillations, but it may also be a possible switching of a minor quantity of crystallites from the low to the high activity state.

The third possibility for the ignition/extinction behavior might be based on the oxygen transport in oxygenated Ruthenium (subsurface oxygen and TSO). The case of silver as a catalyst in the oxidative coupling of methane is one example in the literature for oxygen diffusion to be the rate limiting step in the reaction [43]. In part 3 we described that two channels for oxygen incorporation could be also responsible for the CO oxidation. The highly efficient, defect-mediated channel could, as an activated process, become a rate limiting step at low temperature while at higher temperature a more active state could be reached. This scenario also explains the ignition/extinction behavior. As a consequence the defects of the surface and the bulk would play a crucial rule in the rate of $\mathrm{CO}$ oxidation and hence changing the number of those defects would highly affect the rate of $\mathrm{CO}_{2}$ formation. Thus the healing of defects at higher reaction temperatures [38] could lead to the often observed deactivation and not as proposed to the unlikely creation of the catalytically inactive $\mathrm{RuO}_{2}(100)-\mathrm{c}(2 \times 2)$ surface. 


\section{Conclusion}

Completely oxidized, polycrystalline $\mathrm{RuO}_{2}$ is inactive in the $\mathrm{CO}$ oxidation. Two different stable bulk states of $\mathrm{RuO}_{\mathrm{x}}$ catalysts are identified with in-situ XRD: an active $\mathrm{RuO}_{2}\left(\mathrm{actX} / \mathrm{RuO}_{2}\right)$ and an active $\mathrm{Ru}$ metal catalyst (actY/Ru). Pre-calcined, completely inactive $\mathrm{RuO}_{2}$ shows a very long induction period to establish the active $\mathrm{RuO}_{2}$ catalyst (subO/TSO- $\mathrm{RuO}_{2} / \mathrm{RuO}_{2}$ ) having an apparent activation energy of $(110 \ldots 115) \pm 5 \mathrm{~kJ} / \mathrm{mol}$. Roughening of the $\{101\}$ and $\{111\}$ facets during activation via reduction takes place suggesting these rough surfaces to be the catalytically active ones at this stage. Upon reduction also the $\{110\}$ and $\{100\}$ facets and finally the whole crystal show rough surfaces as well as cracks and holes. This second active bulk state, metallic Ru, exhibits approximately a two to up to fifty times higher activity per mass unit and also a lower apparent activation energy of $(82 \ldots 102) \pm 5 \mathrm{~kJ} / \mathrm{mol}$. It is impossible to quantify the active centers for the reaction and hence to decide which state is intrinsically more active in the $\mathrm{CO}_{2}$ formation. The different apparent activation energies suggest, however, 1) the inequality of both active states and 2) the active metallic Ru catalyst to be the more active surface. The rough surfaces on active $\mathrm{RuO}_{2}$ as catalytically active ones and the different apparent activation energies would cast doubts on the cus- $\mathrm{RuO}_{2}$ sites alone

\section{References}

1. Imbihl, R.; Ertl, G. Chem.Rev. 95 (1995) 697.

2. Bottcher, A.; Niehus, H.; Schwegmann, S.; Over, H.; Ertl, G. J.Phys.Chem.B ,101 (1997) 11185.

3. Peden, C. H. F.; Goodman, D. W. J.Phys.Chem. 90 (1986) 1360.

4. Goodman, D. W.; Peden, C. H. F.; Chen, M. S. Surf.Sci. 601 (2007) L124.

5. Over, H.; Muhler, M.; Seitsonen, A. P. Surf.Sci. 601 (2007) 5659 .

6. Goodman, D. W.; Peden, C. H. F.; Chen, M. S. Surf.Sci. 601 (2007) 5663.

7. Over, H.; Kim, Y. D.; Seitsonen, A. P.; Wendt, S.; Lundgren, E.; Schmid, M.; Varga, P.; Morgante, A.; Ertl, G. Science ,287 (2000) 1474.

8. Assmann, J.; Crihan, D.; Knapp, M.; Lundgren, E.; Loffler, E.; Muhler, M.; Narkhede, V.; Over, H.; Schmid, M.; Seitsonen, A. P.; Varga, P. Angew.Chem.Int.Ed. 44 (2005) 917.

9. Over, H.; Muhler, M. Prog.Surf.Sci. 72 (2003) 3.

10. Assmann, J.; Narkhede, V.; Breuer, N. A.; Muhler, M.; Seitsonen, A. P.; Knapp, M.; Crihan, D.; Farkas, A.; Mellau, G.; Over, H. J.Phys.: Condens.Matter ,20 (2008) .

11. Knapp, M.; Seitsonen, A. P.; Kim, Y. D.; Over, H. J.Phys.Chem.B ,108 (2004) 14392.

12. Bottcher, A.; Rogozia, M.; Niehus, H.; Over, H.; Ertl, G. J.Phys.Chem.B ,103 (1999) 6267.

13. Bottcher, A.; Starke, U.; Conrad, H.; Blume, R.; Niehus, H.; Gregoratti, L.; Kaulich, B.; Barinov, A.; Kiskinova, M. J.Chem.Phys. 117 (2002) 8104.

14. Reuter, K.; Stampfl, C.; Ganduglia-Pirovano, M. V.; Scheffler, M. Chem.Phys.Lett. 352 (2002) 311

15. Vogel, W.; Alonso-Vante, N. J.Cat. 232 (2005) 395. as the active centers. If not the subsurface oxygen and transient surface oxide (subO/TSO) alone an interaction of (subO/TSO) with $\mathrm{RuO}_{2}$ or with the chemisorbed (1x1) oxygen layer (1ML) might be the active ruthenium phases in the CO oxidation.

We can conclude that the $\mathrm{CO}$ oxidation over Ru catalysts is far from simple. The active site(s) of the working catalyst is (are) still unclear as well as the mechanism which may very likely include subsurface oxygen/transient surface oxide species. Furthermore the catalyst exhibits under working conditions a metastable phase mixture rather than a single phase.

\section{Acknowledgements}

We gratefully acknowledge Dr. C.H.F. Peden for helpful discussions and suggestions and (especially R.B.) the team (Lucia Aballe, Luca Gregoratti, Alexei Barinov, and Maya Kiskinova) of the ESCA microscopy beamline at Elettra for the scanning photoemission microscope (SPEM) measurements.
16. He, Y. B.; Knapp, M.; Lundgren, E.; Over, H. J.Phys.Chem.B ,109 (2005) 21825.

17. Blume, R.; Havecker, M.; Zafeiratos, S.; Teschner, D.; Kleimenov, E.; Knop-Gericke, A.; Schlögl, R.; Barinov, A.; Dudin, P.; Kiskinova, M. J.Cat. 239 (2006) 354.

18. Kiskinova, M.; Marsi, K.; Di Fabrizio, E.; Gentili, M. Surf.Rev.Lett. 6 (1999) 265.

19. Seah, M. P.; Dench, W. A. Surface and Interface Analysis ,1 (1979) 1.

20. Lizzit, S.; Baraldi, A.; Groso, A.; Reuter, K.; GandugliaPirovano, M. V.; Stampl, C.; Scheffler, M.; Stichler, M.; Keller, C.; Wurth, W.; Menzel, D. Phys.Rev.B ,63 (2001) 205419-1.

21. Madey, T. E.; Engelhardt, H. A.; Menzel, D. Surf.Sci. 48 (1975) 304

22. Balzar, D.; Popovic, S. J.Appl.Crystallogr. 29 (1996) 16.

23. The surface area of the reduced Ru metal sample (actY/Ru) is probably higher than the value of the re-oxidized $\mathrm{RuO}_{2}$, as could be estimated from the broad XRD peaks and the SEM pictures. Therefore the rates related to the surface area are lower than those shown. The BET measurements are hindered by the mixture with BN, attempts to solve this problem are under way.

24. Narkhede, V.; Assmann, J.; Muhler, M. Z.Phys.Chem. 219 (2005) 979.

25. Assmann, J.; Narkhede, V.; Khodeir, L.; Loffler, E.; Hinrichsen, O.; Birkner, A.; Over, H.; Muhler, M. J.Phys.Chem.B ,108 (2004) 14634

26. Blume, R.; Niehus, H.; Conrad, H.; Bottcher, A.; Aballe, L.; Gregoratti, L.; Barinov, A.; Kiskinova, M. J.Phys.Chem.B ,109 (2005) 14052 
27. Over, H.; Seitsonen, A. P.; Lundgren, E.; Smedh, M.; Andersen, J. N. Surf.Sci. 504 (2002) L196.

28. Kim, Y. D.; Seitsonen, A. P.; Over, H. Surf.Sci. 465 (2000) 1.

29. Kim, Y. D.; Seitsonen, A. P.; Wendt, S.; Wang, J.; Fan, C.; Jacobi, K.; Over, H.; Ertl, G. J.Phys.Chem.B ,105 (2001) 3752.

30. Fan, C. Y.; Wang, J.; Jacobi, K.; Ertl, G. J.Chem.Phys. 114 (2001) 10058

31. Stampfl, C. Catal.Today, 105 (2005) 17.

32. Reuter K. in Nanocatalysis: Principles, Methods, Case Studies, Springer: Berlin, 2006; pp. 343-376.

33. Kim, Y. D.; Over, H.; Krabbes, G.; Ertl, G. Top.Catal. 14 (2001) 95.

34. Rosenthal, D.; Zizak, I.; Darowski, N.; Magkoev, T. T.; Christmann, K. Surf.Sci. 600 (2006) 2830.
35. Beck, T. J.; Klust, A.; Batzill, M.; Diebold, U.; Di Valentin, C.; Selloni, A. Phys.Rev.Lett. 93 (2004) 036104-1.

36. Dulub, O.; Di Valentin, C.; Selloni, A.; Diebold, U. Surf.Sci. 600 (2006) 4407.

37. Over, H.; Seitsonen, A. P.; Lundgren, E.; Schmid, M.; Varga, P. Surf.Sci. 515 (2002) 143.

38. Blume, R.; Niehus, H.; Conrad, H.; Bottcher, A. J.Phys.Chem.B,108 (2004) 14332.

39. Blume, R.; Christen, W.; Niehus, H. J.Phys.Chem.B ,110 (2006) 13912.

40. Kiss, J. T.; Gonzalez, R. D. J.Phys.Chem. 88 (1984) 892.

41. Onken, H. U.; Wicke, E. Z.Phys.Chem. 165 (1989) 23.

42. Reuter, K.; Scheffler, M. Phys.Rev.B ,73 (2006) 045433-1.

43. Nagy, A. J.; Mestl, G.; Schlögl, R. J.Cat. 188 (1999) 58. 